\title{
Comparative Analysis of Voltage Control Signal Techniques for Single Phase Inverter
}

\author{
Athar Hanif, Asim Mukhtar, Umar Farooq, and Abid Javed
}

\begin{abstract}
In this paper, an experimental study is carried out to investigate the performance of various voltage control signal techniques for single phase PWM inverter. These techniques include single pulse width modulation, multiple pulse width modulation, sinusoidal pulse width modulation, modified sinusoidal pulse width modulation and phase displacement control. The performance of these carrier schemes are evaluated in terms of harmonic factor, total harmonic distortion and lowest order harmonic through simulation runs in MATALAB/Simulink. The technique with better harmonic spectrum is then implemented using an inexpensive and readily available AT89S52 microcontroller which generates the gating signals including dead time for switching devices comprising the inverter. The study can be employed for teaching the concepts of carrier schemes to undergraduate students taking the course of power electronics
\end{abstract}

Index Terms - Control signal techniques, matlab/simulink, microcontroller at89s52, pulse width modulation, single phase inverter

\section{INTRODUCTION}

This paper provides the analysis of different voltage control signal techniques for single phase inverter[1] and the voltage control signal technique with least harmonic contents is implemented using microcontroller. A number of PWM techniques have been presented to obtain variable voltage and variable frequency supply [2]. The inverter generates AC output voltage from a DC input voltage source. The power semiconductor switches can be BJTs, thyristors, MOSFETs, IGBTs etc. The option of power semiconductor switch will depend on rating necessities and simplicity with which the device can be turned on and off. A single-phase inverter will contain two or four power switches arranged in half-bridge or full-bridge topologies $[1,3,4]$. Half-bridges have the maximum AC output voltage restricted to half the value of the full DC input source voltage and may require a centre tapped source. Full-bridges have the full DC source voltage as the maximum AC load voltage. Where DC input source voltage is low, e.g. $12 \mathrm{~V}$ or $24 \mathrm{~V}$ [4], the voltage drop across the conducting power switches is important and should be taken into account both in computation and in choice of the switch.

The AC load voltage of the DC-AC converter is basically a square wave, but PWM methods can be used to lessen the harmonics and generate a quasi-sine wave. If higher $\mathrm{AC}$ voltages than the DC source voltage are required, then the

Manuscript received March 9, 2011; revised June 31, 2011.

The authors are with the Electrical Engineering Department, The University of Lahore, Raiwind Road, Lahore Pakistan. (e-mail: athar@ uol.edu.pk; asimmukhtar@ymail.com; engr.umarfarooq@yahoo.com, abid@uol.edu.pk).
DC-AC converter will need a step-up transformer. The output frequency of the DC-AC converter is restricted by the speed at which the power devices are turned on and off, in other terminology by the pulse repetition frequency of the gate, or base, driver circuit.

Thyristors, semi-controlled switch would only be preferred in very high power DC-AC converters, since on the source side there is no voltage zero, and a forced commutation circuit would be required to turn the thyristor off. The preferred switching device is an IGBT, but could be any switching device, the alternative being determined by accessibility of necessary rating and simplicity of turn-on and turn-off. Care must be in use not to have two switching devices 'on' jointly, shorting out the DC-link voltage. There must be either a blanking/dead-time between switching devices or a delay circuit to guarantee this does not take place.

\section{II.PERFORMANCE PARAMETERS}

The output of practical inverters contains harmonics and the superiority of an inverter is usually evaluated in the terms of the subsequent performance parameters [1].

\section{A. Harmonic Factor}

The harmonic factor (of the nth harmonic), which is measure of individual harmonic contribution, is defined as

$$
H F_{n}=\frac{V_{\text {on }}}{V_{o 1}} \quad \text { for }>1
$$

where $\mathrm{V}_{\mathrm{ol}}$ is the fundamental component's rms value and $\mathrm{V}_{\text {on }}$ is the nth harmonic component's rms value.

\section{B. Total Harmonic Distortion}

The total harmonic distortion, which is a measure of closeness in shape between a waveform and its fundamental component, is defined as

$$
T H D=\frac{1}{V_{o 1}}\left(\sum_{n=2,3, \ldots}^{\infty} V_{o n}^{2}\right)^{1 / 2}
$$

\section{Distortion Factor}

THD gives the total harmonic content, but it does not specify the level of each harmonic component if a filter is worn at the inverter's output, the higher order harmonics would be attenuated more effectively. Therefore, knowledge of both frequency and magnitude of each harmonic is important. The DF indicates the amount of HD that stays in the exacting waveform after harmonic of that waveform have been subjected to a second order attenuation. Thus DF is determination of efficiency in reducing useless harmonics lacking of having to identify the value of second order load filter and is defined as 
$D F=\frac{1}{V_{o 1}}\left[\sum_{n=2,3, \ldots}^{\infty}\left(\frac{V_{o n}}{n^{2}}\right)^{2}\right]^{1 / 2}$

The DF of each (or nth) harmonic component is defined as $D F_{n}=\frac{V_{o n}}{V_{o 1} n^{2}} \quad$ for $n$

\section{D.Lowest Order Harmonic}

The LOH is that harmonic component whose frequency is closest to the fundamental one, and its amplitude is greater than or equal to $3 \%$ of the fundamental component.

\section{Control Signal Techniques}

A pulse width modulation (PWM) switching plan is developed through carrier modification, which eliminates the constraint in the fundamental component of a expected switching scheme in the linear region [5]. The proposed approach is appropriate for single-phase full bridge inverter. The performance estimation and judgment are based on the fundamental component, the total harmonic distortion (THD) and number of pulses per cycle. There is a variety of techniques to change the inverter gain. The most efficient method to control the inverter gain is to include PWM control within the inverters [1]. The generally used techniques are

\section{Simulink ImPlementation Of Voltage Control Signal TeChNiques For Single Phase InVERTER}

This section contains the simulation results of different voltage control signal techniques for single phase inverter using Matlab/Simulink.

\section{A. Single Pulse Width Modulation}

The Simulink schematic for single pulse width modulation control technique for single phase full bridge inverter is shown in fig. 1 . The Results of harmonic analysis are shown in table 1.

In SPWM control, only one pulse per half cycle is available.

Fig. 2 and 3 shows the pulses for each half cycle Fig. 4 contains the output wave form.

TABLE I: RESULTS FOR SPWM

\begin{tabular}{|l|l|l|l|l|}
\hline $\mathrm{n}$ & $V_{\text {on }}$ & $H F_{n}$ & $D F_{n}$ & $T H D$ \\
\hline 1 & 258.78 & & & \\
\hline 3 & 35.73 & 0.138071 & 0.0153 & \\
\hline 5 & 21.44 & 0.08285 & 0.0033 & \\
\hline 7 & 18.97 & 0.07331 & 0.0015 & 0.4616 \\
\hline 9 & 16.75 & 0.1111 & 0.0014 & \\
\hline 11 & 9.763 & 0.03773 & 0.00031 & \\
\hline 13 & 8.214 & 0.03174 & 0.00019 & \\
\hline
\end{tabular}

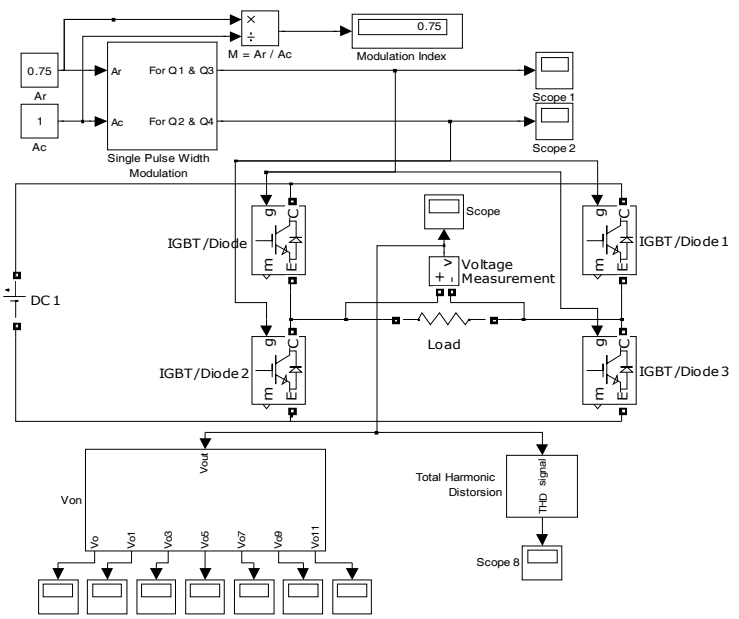

Fig. 1. Simulink model for SPWM

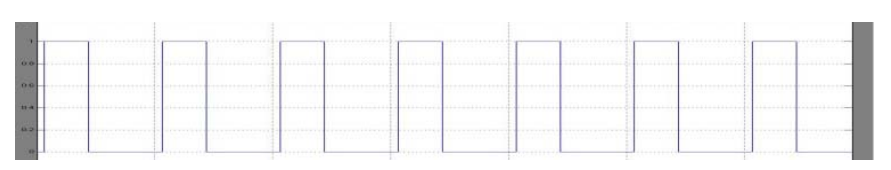

Fig. 2. Q1 and Q3 gating signal for SPWM

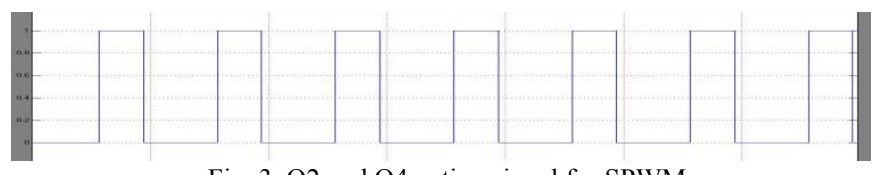

Fig. 3. Q2 and Q4 gating signal for SPWM

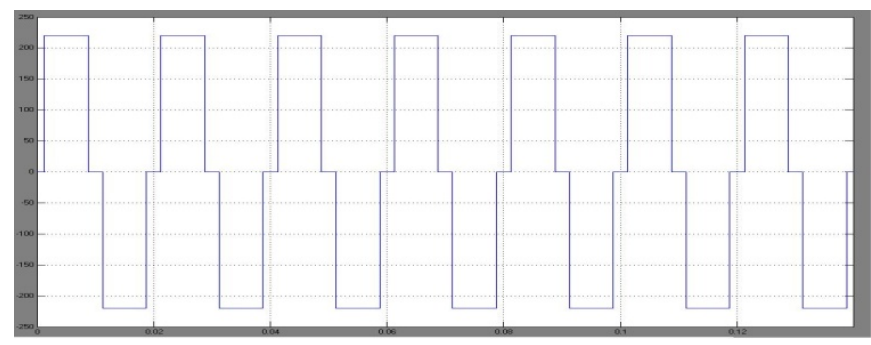

Fig. 4. Output voltage $\left(\mathrm{v}_{\mathrm{ou}} \mathrm{t}\right)$ for spwm

In single pulse width technique, total harmonic distortion is $46.16 \%$ at modulation index of 0.75 . The AC gain of single pulse width is very high but the low order harmonic contents are also high. The fundamental component magnitude is 258.78 when $220 \mathrm{VDC}$ is applied at input. Spectrum for $\mathrm{V}_{\text {on }}$, $\mathrm{HF}_{\mathrm{n}}$ and $\mathrm{DF}_{\mathrm{n}}$ are shown in fig. 5, 6, and 7 respectively.

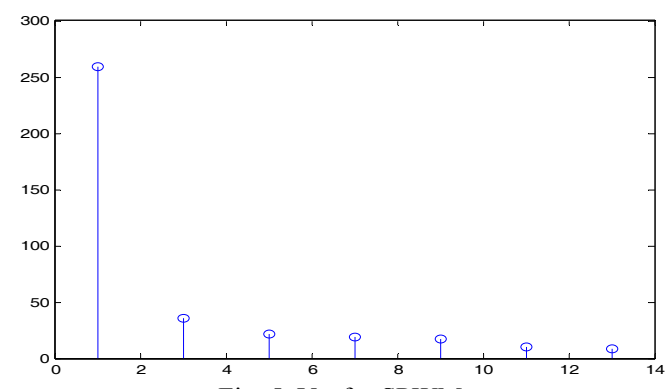

Fig. 5. $\mathrm{V}_{\text {on }}$ for SPWM 


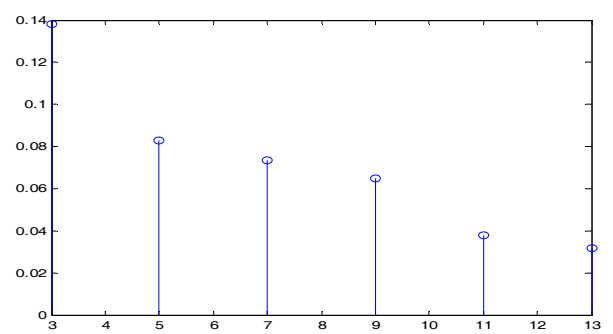

Fig. 6. $\mathrm{HF}_{\mathrm{n}}$ for SPWM

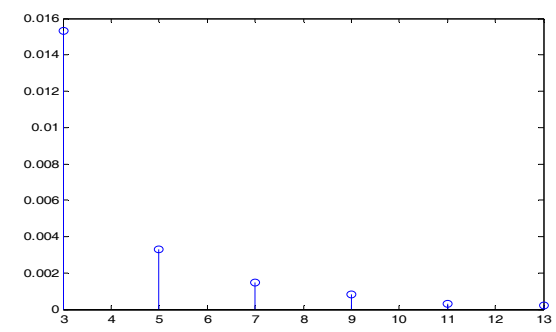

Fig. 7. $\mathrm{DF}_{\mathrm{n}}$ for $\mathrm{SPWM}$

\section{B. Multiple Pulse Width Modulation}

The Simulink schematic for multiple phase pulse width modulation control technique for single phase full bridge inverter is shown in fig. 8. The Results of Harmonic analysis of single phase inverter are shown in table 2.

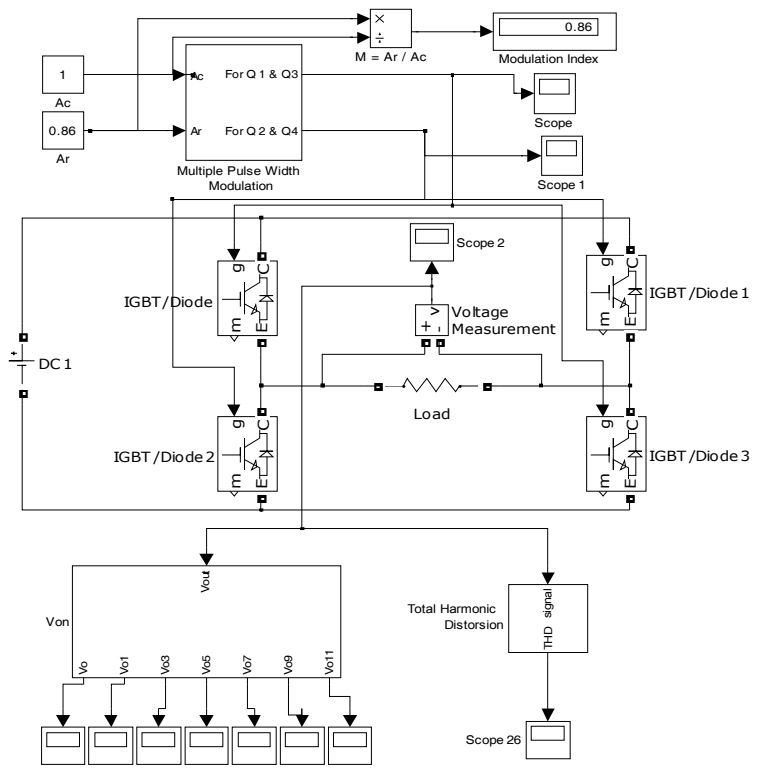

Fig. 8. Simulink model for MPWM

In multiple pulse width technique, total harmonic distortion is $38.6 \%$ at modulation index of 0.86 . The $\mathrm{AC}$ gain of multiple pulse width is high but is lower than that of single pulse width modulation technique. The low order harmonic contents are also high. The fundamental component magnitude is 230 when $220 \mathrm{VDC}$ is applied at input.

TABLE II: RESULTS FOR MPWM

\begin{tabular}{|l|l|l|l|l|}
\hline $\mathrm{n}$ & $V_{\text {on }}$ & $H F_{n}$ & $D F_{n}$ & THD \\
\hline 1 & 230 & & & \\
\hline 3 & 80 & 0.34783 & 0.038647 & \\
\hline 5 & 53.5 & 0.23261 & 0.0093044 & \\
\hline 7 & 50 & 0.21739 & 0.0044366 & 0.386 \\
\hline 9 & 40 & 0.17391 & 0.00215 & \\
\hline 11 & 26 & 0.113044 & 0.0009346 & \\
\hline 13 & 8 & 0.034783 & 0.0002057 & \\
\hline
\end{tabular}

The pulses for each half cycle are shown in fig. 9 and 10 Fig. 11 contains the output wave form.

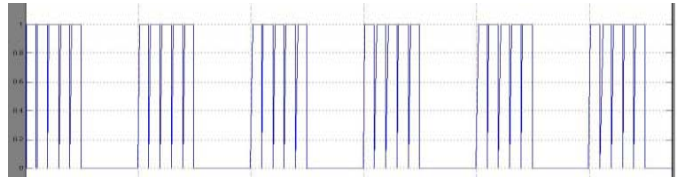

Fig. 9. Q1 and Q3 gating signal for MPWM

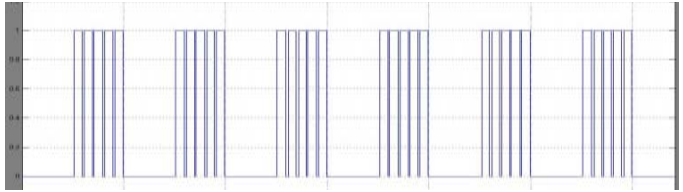

Fig. 10. Q2 and Q4 gating signal for MPWM

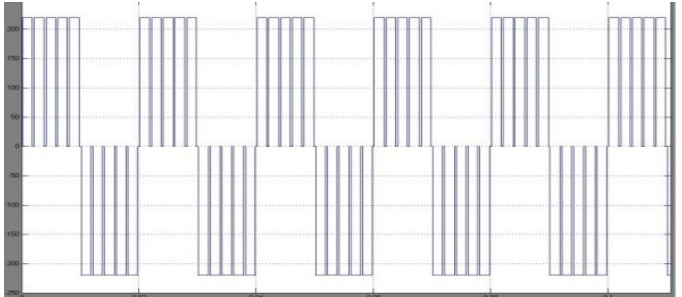

Fig. 11. Output voltage $\left(\mathrm{V}_{\text {out }}\right)$ for MPWM

Spectrum for $\mathrm{V}_{\mathrm{on}}, \mathrm{HF}_{\mathrm{n}}$ and $\mathrm{DF}_{\mathrm{n}}$ are shown in fig. 12, 13 , and 14 respectively.

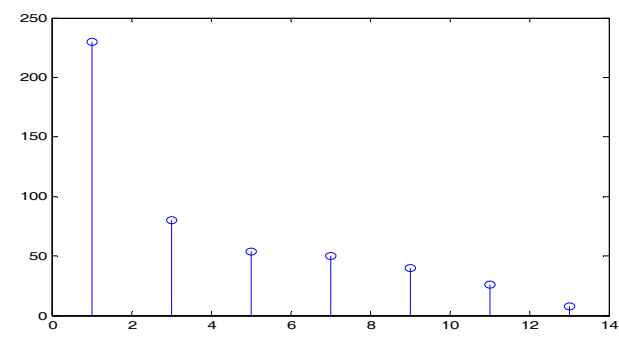

Fig. 12. $\mathrm{V}_{\text {on }}$ for MPWM

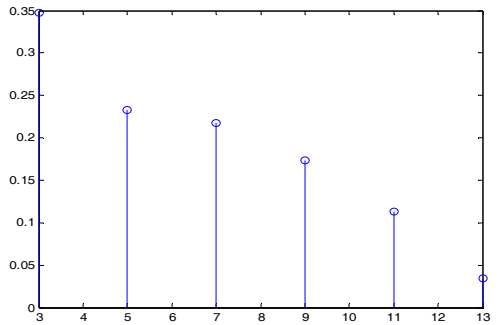

Fig. 13. $\mathrm{HF}_{\mathrm{n}}$ for MPWM

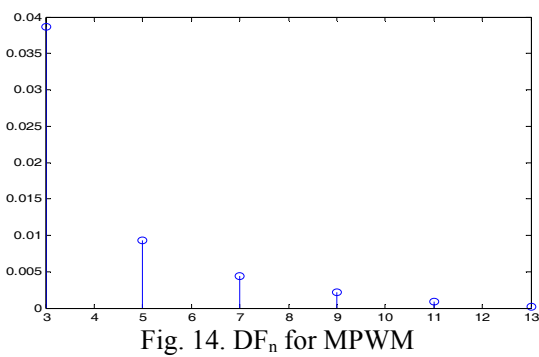

\section{Sinusoidal Pulse Width Modulation}

The Simulink schematic for sinusoidal phase pulse width modulation control technique for single phase full bridge inverter is shown in fig. 15. The Results of Harmonic analysis of single phase inverter are shown in table 3 . 


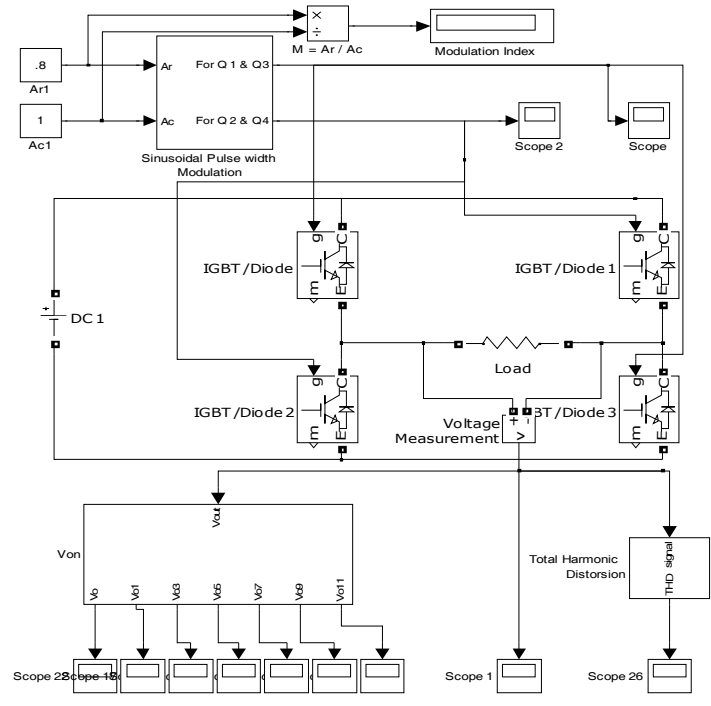

Fig. 15. Simulink model for SiPWM

TABLE III: RESULTS FOR SIPWM

\begin{tabular}{|l|l|l|l|l|}
\hline $\mathrm{n}$ & $V_{\text {on }}$ & $H F_{n}$ & $D F_{n}$ & THD \\
\hline 1 & 176 & & & \\
\hline 3 & 0.003 & $1.7046 \mathrm{E}-05$ & $1.8939 \mathrm{E}-06$ & \\
\hline 5 & 0.0045 & $2.5568 \mathrm{E}-05$ & $1.0227 \mathrm{E}-06$ & \\
\hline 7 & 0.1119 & 0.000636 & $1.2975 \mathrm{E}-05$ & 0.2181 \\
\hline 9 & 2.795 & 0.015881 & 0.0001961 & \\
\hline 11 & 30.68 & 0.1743182 & 0.0014407 & \\
\hline 13 & 69.2 & 0.393182 & 0.0023265 & \\
\hline
\end{tabular}

The pulses for each half cycle are shown in fig.16 and 17. Fig. 18 contains output voltage waveform.

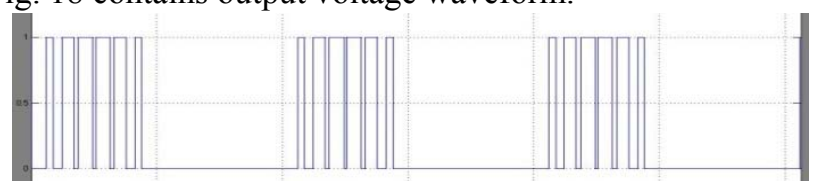

Fig. 16. Q1 and Q3 gating signal for SiPWM

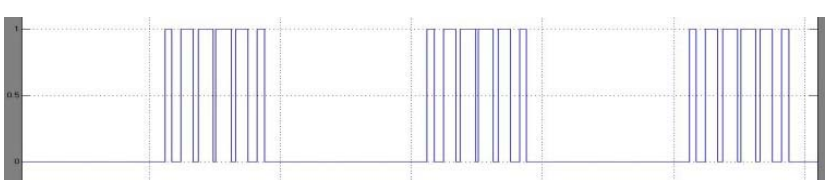

Fig. 17. Q2 and Q4 gating signal for SiPWM

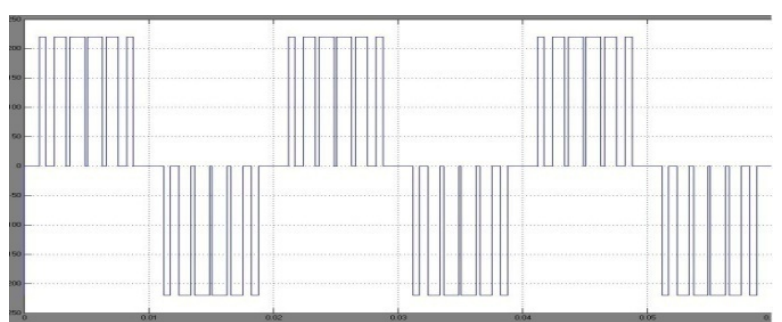

Fig. 18. Output voltage $\left(\mathrm{V}_{\text {out }}\right)$ for SiPWM

In sinusoidal pulse width technique, total harmonic distortion is $21.81 \%$ at modulation index of 0.8 . The $\mathrm{AC}$ gain of sinusoidal pulse width is high but is lower than that of single pulse width modulation technique and multiple pulse width technique. The low order harmonic contents are very low as compared to that of single pulse width modulation technique and multiple pulse width technique. The fundamental component magnitude is 176 when $220 \mathrm{VDC}$ is applied at input. Spectrum for $V_{o n}, H F_{n}$ and $D F_{n}$ are shown in fig. 19, 20, and 21 respectively.

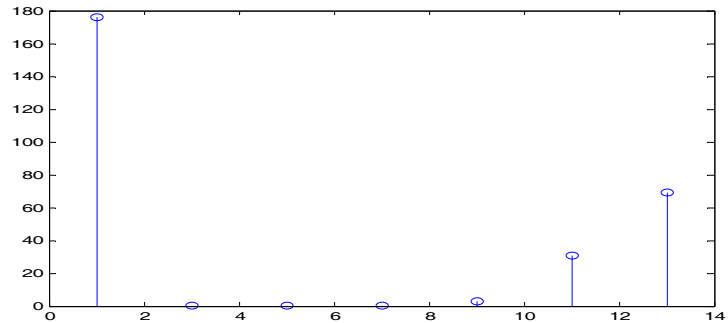

Fig. 19. $\mathrm{V}_{\text {on }}$ for SiPWM

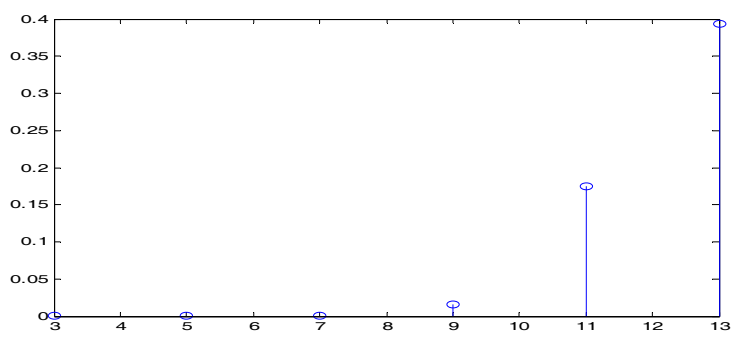

Fig. 20. $\mathrm{HF}_{\mathrm{n}}$ for $\mathrm{SiPWM}$

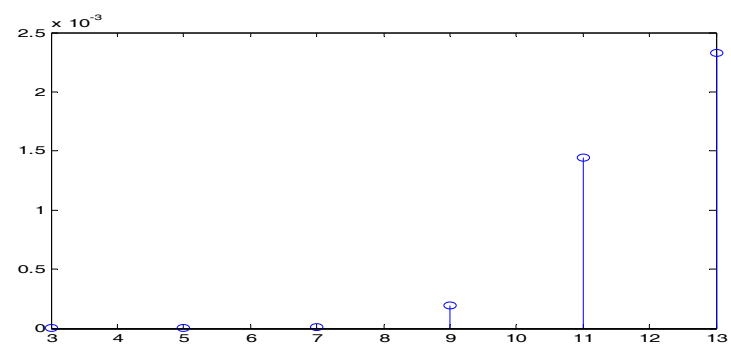

Fig. 21. $\mathrm{DF}_{\mathrm{n}}$ for $\mathrm{SiPWM}$

\section{Modified Sinusoidal PWM}

The Simulink schematic for sinusoidal phase pulse width modulation control technique for single phase full bridge inverter is shown in fig. 22. The Results of Harmonic analysis of single phase inverter are shown in table 4.

The pulses for each half cycle are shown in fig. 23 and 24. Fig. 25 contains the output voltage waveform.

\begin{tabular}{|l|l|l|l|l|}
\multicolumn{5}{l}{ TABLE IV: RESULTS FOR MSIPWM } \\
\hline $\mathrm{n}$ & $\mathrm{V}_{\text {on }}$ & $\mathrm{HF}_{\mathrm{n}}$ & $\mathrm{DF}_{\mathrm{n}}$ & THD \\
\hline 1 & 208.84 & & & \\
\hline 3 & 18.3 & 0.087627 & 0.0097363 & \\
\hline 5 & 1.14 & 0.005459 & 0.0002184 & \\
\hline 7 & 0.8 & 0.00383 & $7.8177 \mathrm{E}-05$ & 0.2888 \\
\hline 9 & 0.128 & 0.000613 & $7.56678 \mathrm{E}-06$ & \\
\hline 11 & 19.68 & 0.094235 & 0.0007788 & \\
\hline 13 & 53.97 & 0.258428 & 0.0015292 & \\
\hline
\end{tabular}

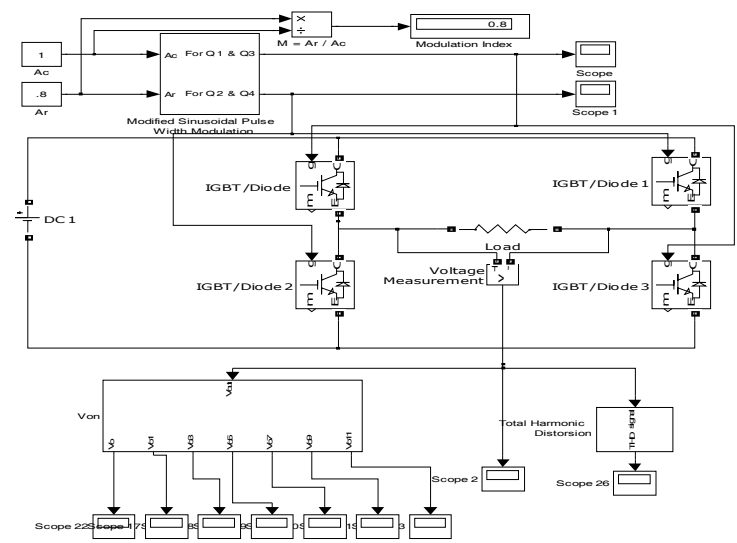

Fig. 22. Simulink model for MSiPWM 


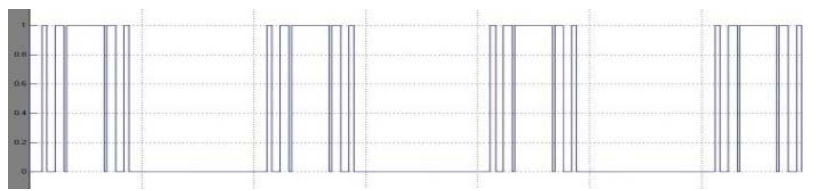

Fig. 23. Q1 and Q3 gating signal for MSiPWM

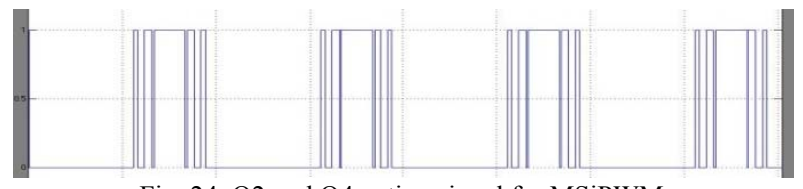

Fig. 24. Q2 and Q4 gating signal for MSiPWM

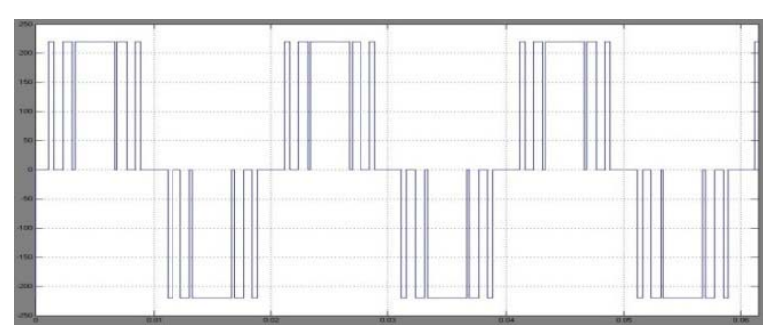

Fig. 25. Output Voltage (Vout) for MSiPWM

In modified sinusoidal pulse width technique, total harmonic distortion is $28.88 \%$ at modulation index of 0.8 . The AC gain of modified sinusoidal pulse width is high but is lower than that of single pulse width modulation technique and multiple pulse width technique. The low order harmonic contents are very low as compared to that of single pulse width modulation technique and multiple pulse width technique. The low order harmonic contents are high as compared to that of sinusoidal pulse width modulation technique. The fundamental component magnitude is 208.84 when $220 \mathrm{VDC}$ is applied at input. Spectrum for $V_{o n}, H F_{n}$ and $D F_{n}$ are shown in fig. 26,27 , and 28 respectively.

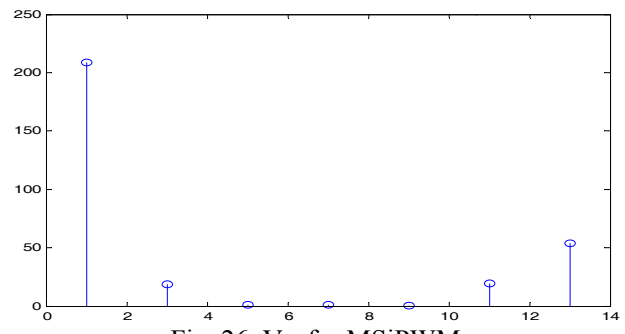

Fig. 26. $\mathrm{V}_{\text {on }}$ for MSiPWM

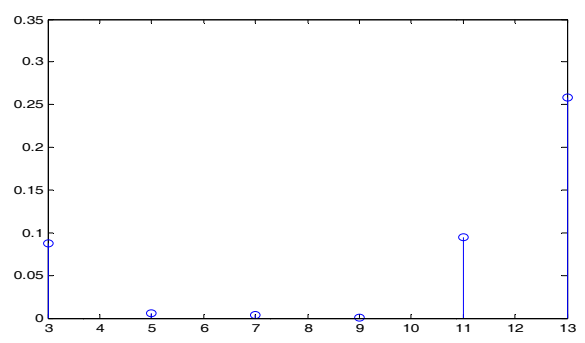

Fig. 27. $\mathrm{HF}_{\mathrm{n}}$ for MSiPWM

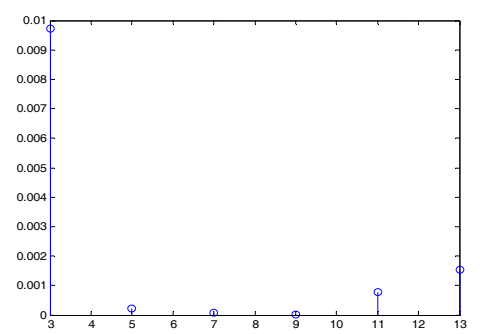

Fig. 28. $\mathrm{DF}_{\mathrm{n}}$ for MSiPWM

\section{E. Phase Displacement Control}

The Simulink schematic for phase displacement control technique for single phase full bridge inverter is shown in fig. 29. The Results of Harmonic analysis of single phase inverter are shown in table 5.

TABLE V: Results For PHASE DisPlacEMENT CONTROL

\begin{tabular}{|l|l|l|l|l|}
\hline $\mathrm{n}$ & $V_{\text {on }}$ & $H F_{n}$ & $D F_{n}$ & THD \\
\hline 1 & 198.07 & & & \\
\hline 3 & 66.1 & 0.3337204 & 0.037080 & \\
\hline 5 & 39.6 & 0.1999293 & 0.0079972 & \\
\hline 7 & 28.3 & 0.1428788 & 0.0029159 & 0.4835 \\
\hline 9 & 22 & 0.1110718 & 0.0013713 & \\
\hline 11 & 18 & 0.090877 & 0.000751 & \\
\hline 13 & 15.25 & 0.076993 & 0.000456 & \\
\hline
\end{tabular}

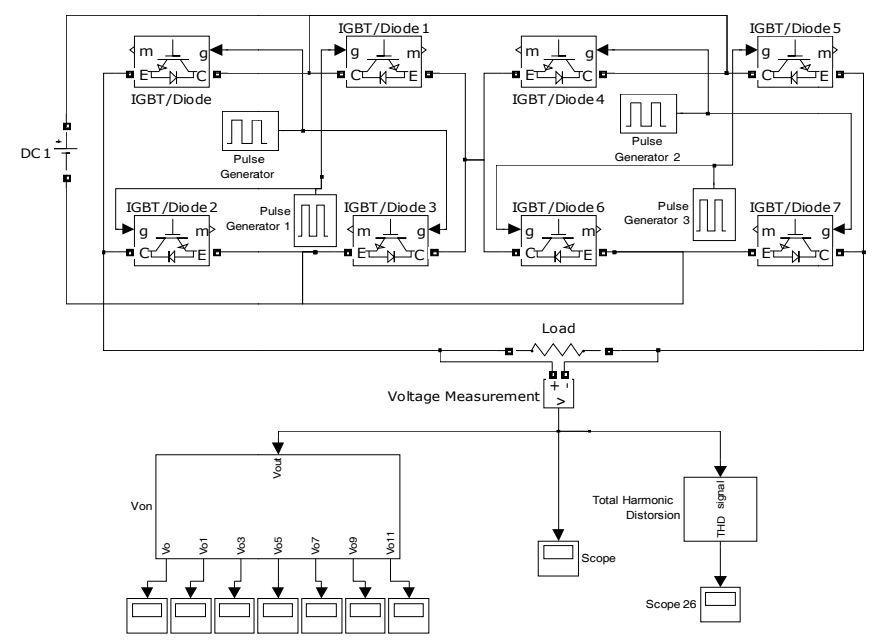

Fig. 29. Simulink model for phase displacement control

Fig. 30 and 31 contains the gating signals for inverter 1 and Fig. 32 and 33 contains the gating signals for inverter 2 .

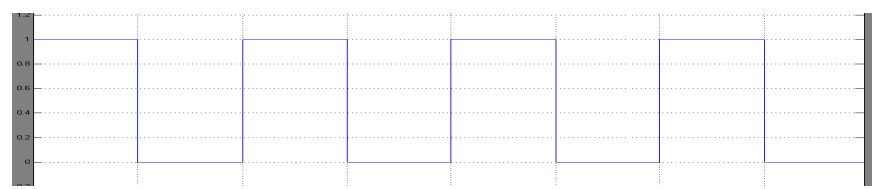

Fig. 30. Gating signal for Q1 and Q3 for inverter 1

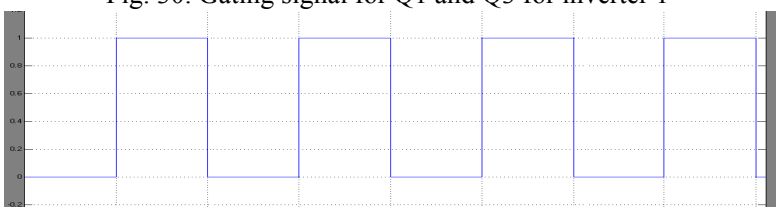

Fig. 31. Gating signal for $\mathrm{Q} 2$ and $\mathrm{Q} 4$ for inverter 1

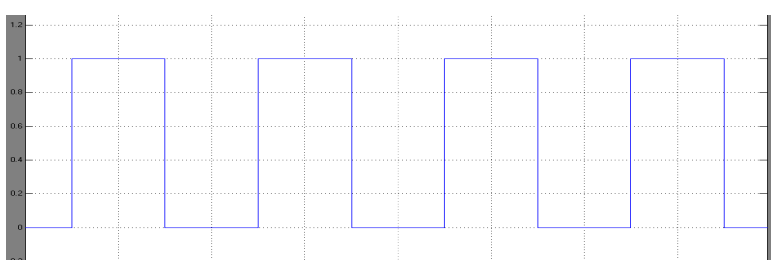

Fig. 32. Gating signal for Q1 and Q3 for inverter 2

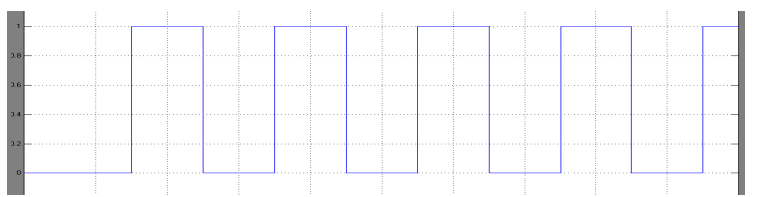

Fig. 33. Gating signal for Q2 and Q4 for inverter 2 
In Phase Displacement Control, total harmonic distortion is $48.35 \%$. The AC gain of Phase Displacement Control is very low as compared to that of single pulse width modulation technique and multiple pulse width technique, but the low order harmonic contents are also high. The fundamental component magnitude is 198.07 when $220 \mathrm{VDC}$ is applied at input. Figure 34 shows the Output waveform for Phase control technique. Spectrum for $V_{o n}, H F_{n}$ and $D F_{n}$ are shown in fig. 35, 36 and 37 respectively.

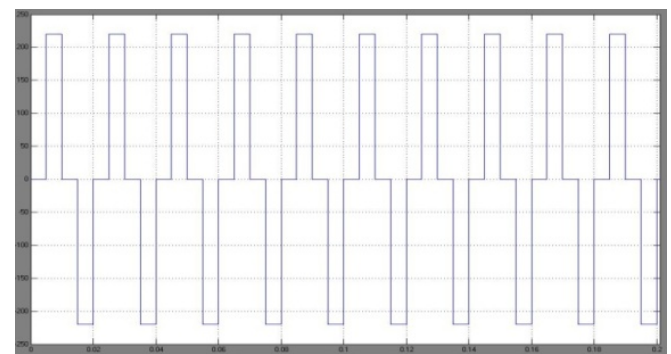

Fig. 34. Output voltage for phase displacement control

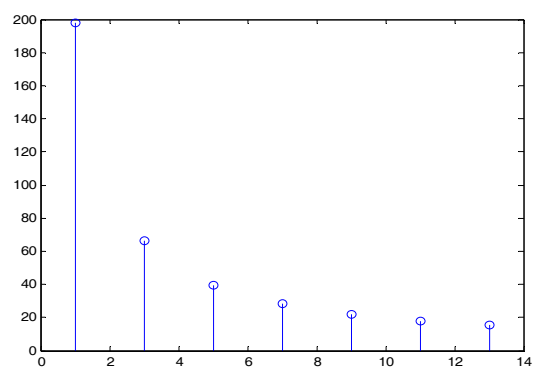

Fig. 35. $\mathrm{V}_{\text {on }}$ for phase displacement control

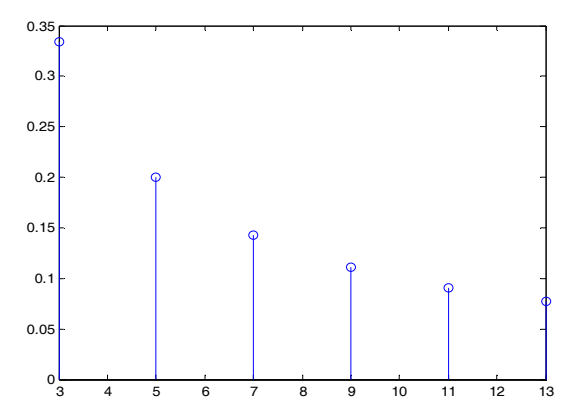

Fig. 36. $\mathrm{HF}_{\mathrm{n}}$ for phase displacement control

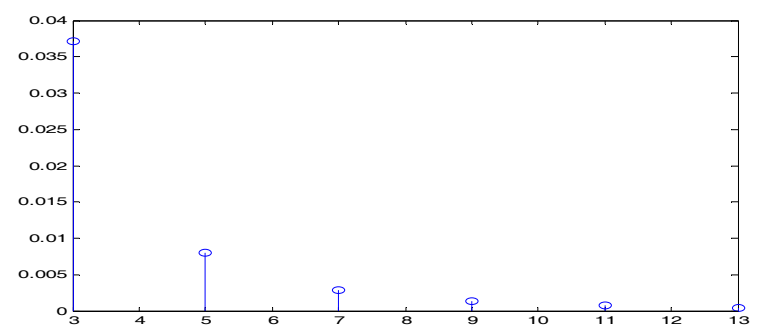

Fig. 37. $\mathrm{DF}_{\mathrm{n}}$ for phase displacement control

\section{F. Comparison of Voltage Control Signal Techniques}

Table. 6 present the comparison of voltage control signal techniques with the help of their performance parameter especially amplitude of the fundamental component and THD.

TABLE VI: COMPARISON OF VOLTAGE CONTROL SIGNAL TECHNIQUES

\begin{tabular}{|l|l|l|l|l|l|}
\hline $\begin{array}{l}\text { Performance } \\
\text { Parameter }\end{array}$ & SPWM & MPWM & SiPWM & MSiPWM & PDM \\
\hline $\mathrm{V}_{\mathrm{o} 1}$ & 258.78 & 230 & 176 & 208.78 & 198.02 \\
\hline THD & $46.16 \%$ & $38.60 \%$ & $21.81 \%$ & $28.88 \%$ & $48.35 \%$ \\
\hline
\end{tabular}

\section{HARDWARE IMPLEMENTATION}

\section{A. Introduction}

SiPWM is extensively adopted for power electronics circuit to obtain digital control so that a series of voltage control pulses can be created by means of the OFF and ON of the power semiconductor devices. The PWM DC-AC converter has become the major selection for power electronic circuits for decades, due to its circuit ease and strong power scheme. SiPWM control signal technique is normally worn for industrialized applications [6]. SiPWM technique is described by stable amplitude pulses through dissimilar duty cycle intended for every period. The breadths of these pulses are altered to get inverter AC load voltage control and toward lessen its harmonic content. SiPWM is generally used scheme in controlling the motor and DC-AC converter application.

In this paper a SiPWM voltage control category is preferred as this voltage control technique presents the benefit of efficiently doubling-up the switching rate of a DC-AC converter voltage. Conventionally, to produce SiPWM signal, carrier signal of triangle shape is generated and compared by other signal known as modulating signal, frequency of modulated signal is the desired output frequency. The projected plan is to change the straight technique by means of microcontroller. The adaptation of the microcontroller gets the elasticity to modify the real-time control program without extra modifications in hardware. It is of small size and low cost control circuit for the single phase inverter.

To achieve the control system an Atmel AT89S52 microcontroller was used [7]. Fig. 38 offered the AT89S52 assignment of pins for the control scheme of SiPWM in single phase full bridge inverter system. The Atmel microcontroller is used as the compensator circuit to build the plan of controller easier, more trustworthy and mainly to decrease their size and components. The control circuit that can do all for a whole circuit is implemented with the help of small separate Atmel microcontroller entrenched in the DC-AC converter system.

\section{B. Single Phase Full Bridge Inverter}

The DC-AC converter, also acknowledged as inverter modifies DC source voltage to AC output voltage at desired AC load voltage as well as frequency [8]. The ac load voltage of DC-AC converter has a square waveform, not a sinusoidal waveform but can be made to closely approximate this desire waveform. Fig. 39 presents the circuit for a single phase full bridge inverter. It is an electronic power converter that is important as a boundary between the power input and the load. The inverter presented in fig. 39 has a DC voltage source, four switching elements Q1, Q2, Q3 and Q4 and load. The switching element accessible now a day, such as BJTs, GTOs, MOSFETs, IGBTs, MCT's and SIT's can be worn as a switch. They are substituting the relays, magnetic switches and other magnetic components as the inverter switching devices. This makes use of microcontroller becomes more significant. The full bridge single phase inverter has two legs, left or right or ' $A$ ' phase leg and 'B' phase leg.

Each leg consists of two power semiconductor devices connect in series. The output is taken from the midpoints of the phase leg A and phase leg B. Each power semiconductor 
switch has an anti-parallel diode. The diodes provide another pathway for the output ac current if the power devices are forced to turn OFF. For example, if lower IGBT in the ' $A$ ' phase leg is conducting and carrying current towards the negative DC bus, this current would 'commutate' into the diode across the upper IGBT of the' A' phase leg, if the lower IGBT is OFF. Control of inverter's circuit is done by changing the on time of the phase leg A and phase leg B lower and upper IGBT by the provision of, both are not turned $\mathrm{ON}$ at the similar time, to keep away from a short circuit of DC link.

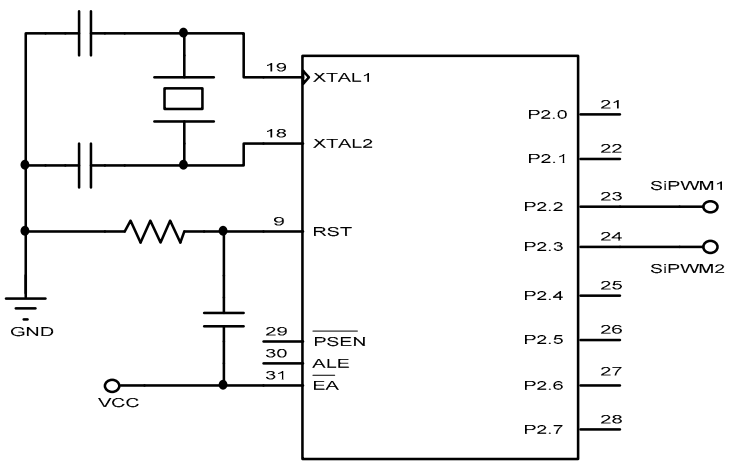

Fig. 38. AT89S52 pins

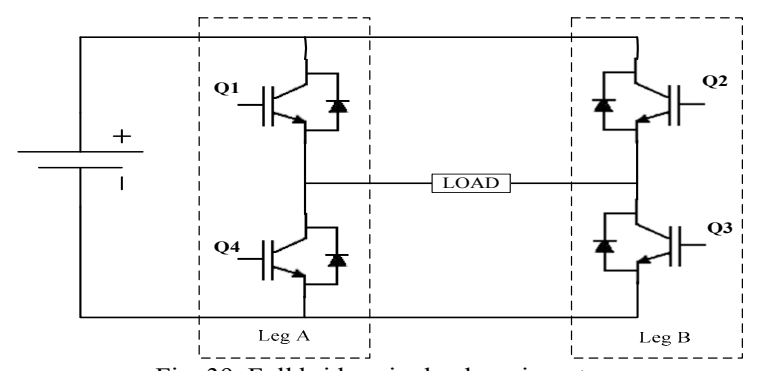

Fig. 39. Full bridge single phase inverter

The switching frequency used in this project is $700 \mathrm{~Hz}$. The software development includes designing suitable switching pulses with the use of the variable frequency and variable duty cycle PWM available inside the microcontroller. It is desired to control the inverter with proper switching pulses. The digital achievement SiPWM is typically obtained by means of a timer based card inside microcontroller. The turn off and turn on time of the switches is determined by this SiPWM control signal. Before this control signal is being generated, proper calculation is done to determine the suitable switching pulses conditions. Fig. 40 shows the switching plan that is worn in this research. The turn OFF and ON device 1 (Q1) and device 4 (Q4) are restricted by SiPWM 1 obtained from port 2.2 of Atmel microcontroller. Whereas the turn OFF and ON device $2(\mathrm{Q} 2)$ and device $3(\mathrm{Q} 3)$ are restricted by SPWM 2 obtained from port 2.3 of Atmel microcontroller. Both SiPWM 1 and SiPWM 2 worn the similar voltage control signal produced through the AT89S52 microcontroller. The difference is only SiPWM 2 control signal is lagging SiPWM 1 near semi cycle or degree of 180 of switching control signal.

\section{System Outline}

The system has a microcontroller circuit for the generation of SiPWM pulses, opto-isolator, gate driving circuit and DC-AC converter circuit. SiPWM signal produced by means of microcontroller desires to be separated for safety and protection between a potentially unsafe and a secure environment. After that outputs are provided to gate driving circuit which includes four self-directed electrically-isolated IGBT drivers. At input side $220 \mathrm{VAC}$ is rectified to produce DC voltages which acts as DC supply voltage for Single Phase Full Bridge Inverter for conversion from VDC to VAC. Capacitor is used as a filter to minimize the ripples in DC voltages to get almost pure DC voltages. Capacitor is connected on DC bus parallel to Inverter circuit. Fig.41. shows the over-all diagram of the system.

\section{D.Isolation Circuit}

To provide isolation between the microcontroller circuit, that is operated at $5 \mathrm{~V}$ and inverter circuit, which has high voltage and current rating, isolation circuits are used. This is implemented with the help of opto-coupler 817c. Fig. 42 presents the opto-coupler circuit.

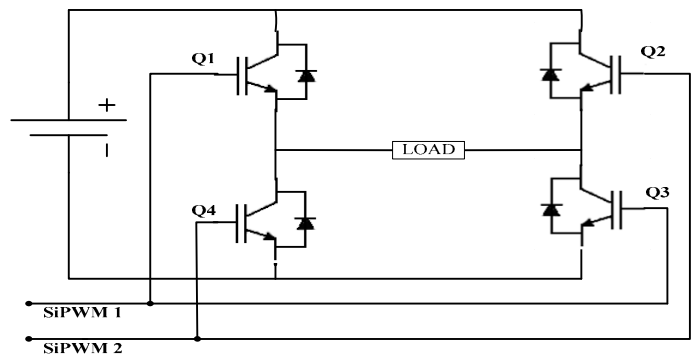

Fig. 40. Switching plan for single phase full bridge inverter

\section{E. Gate Driver Circuit}

Mainly, fundamental categories for gate driving circuits are two. One is high side driver and other is low side driver. Meaning of high side driver is that the source of switch, IGBT of inverter circuit can hang between DC-link and ground. Meaning of low side driver is that source of the device; IGBT is at all times coupled to ground.

IC IR2110 is used for the gate driving circuit [9]. Fig. 43 shows the design of the gate driver circuits employing the bootstrap capacitor and, an ultra fast diode, UF4005.

\section{F. Overall Circuit}

Combination of all the above sections as one will shape the overall circuit of the single phase inverter of full bridge type. As presented in fig. 44, the overall circuit schematic diagram contains DC input, PWM inputs and isolation circuit.

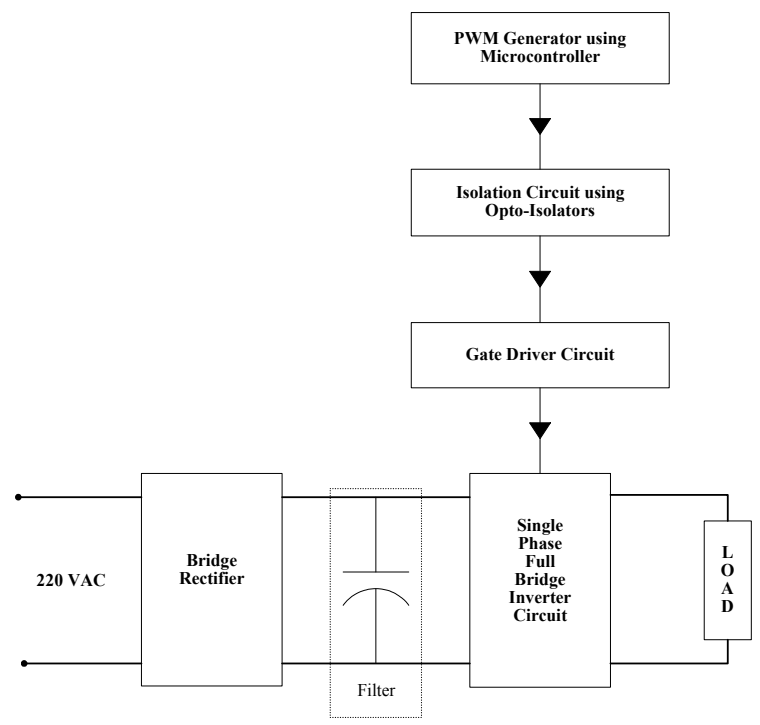

Fig. 41. Flow of hardware development 


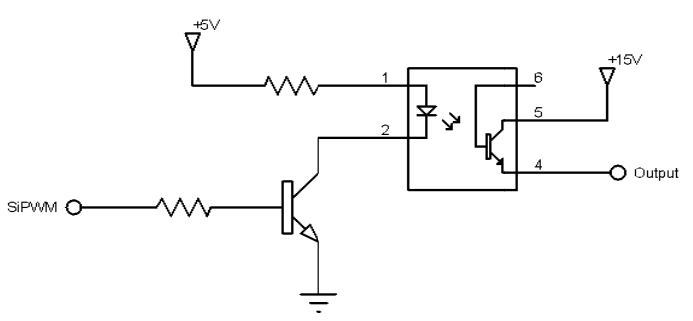

Fig. 42. Isolation circuit

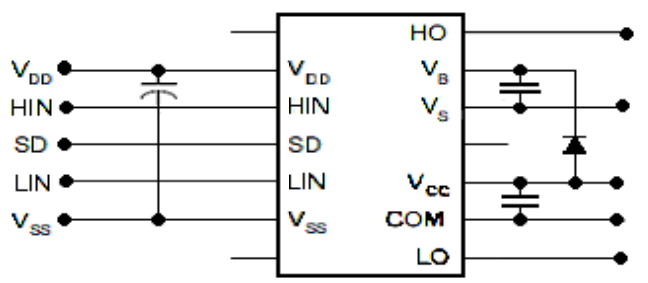

Fig. 43. Gate driving circuit

\section{G.Experimental Results}

Fig. 47 and 48 shows the gating pulses using microcontroller and fig. 49 shows the AC output voltage waveform.

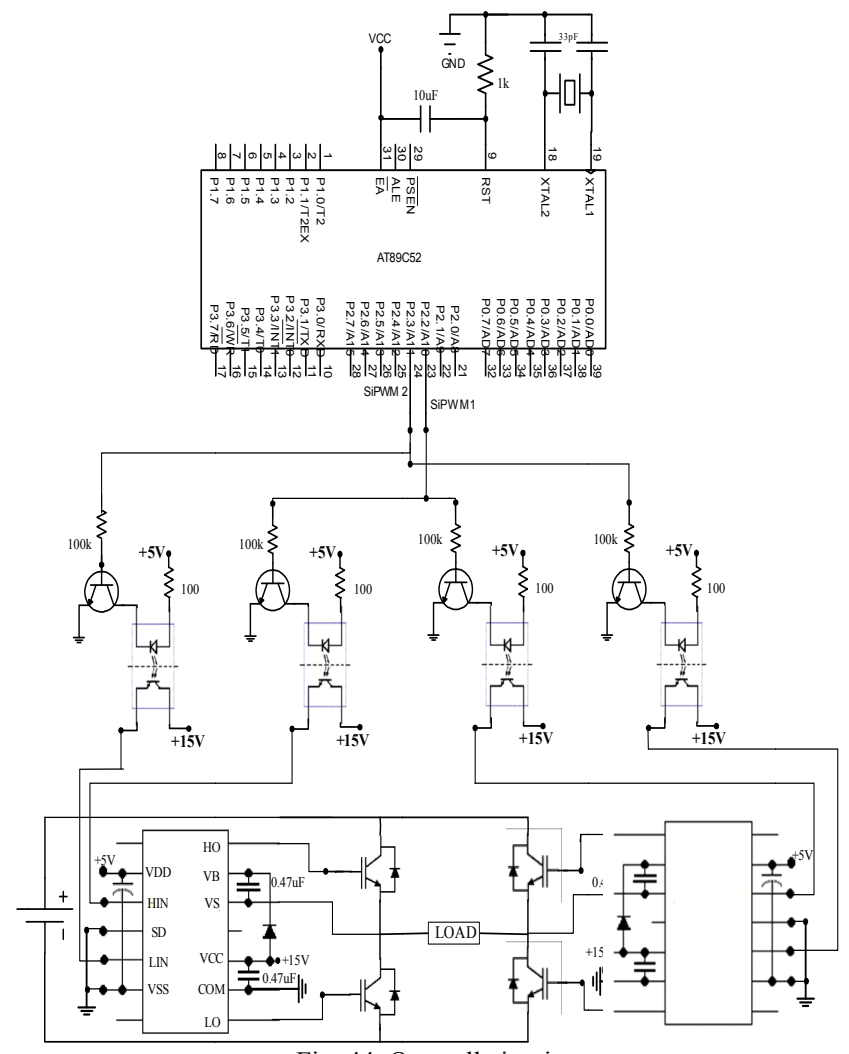

Fig. 44. Over-all circuit

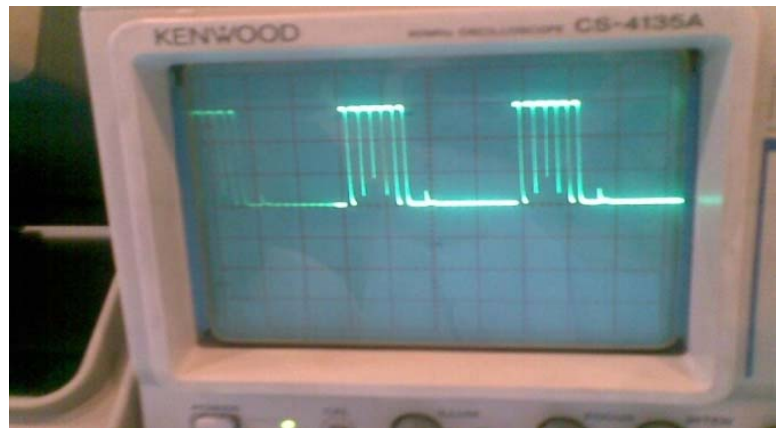

Fig. 45. Gating signal for Q1and Q3

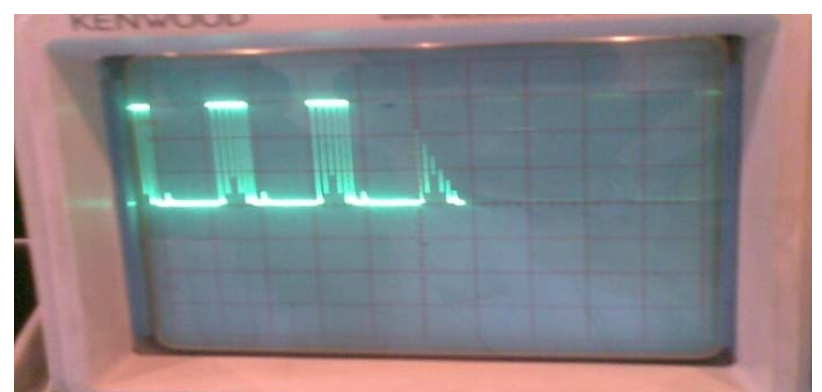

Fig. 46. Gating signal for Q2 and Q4

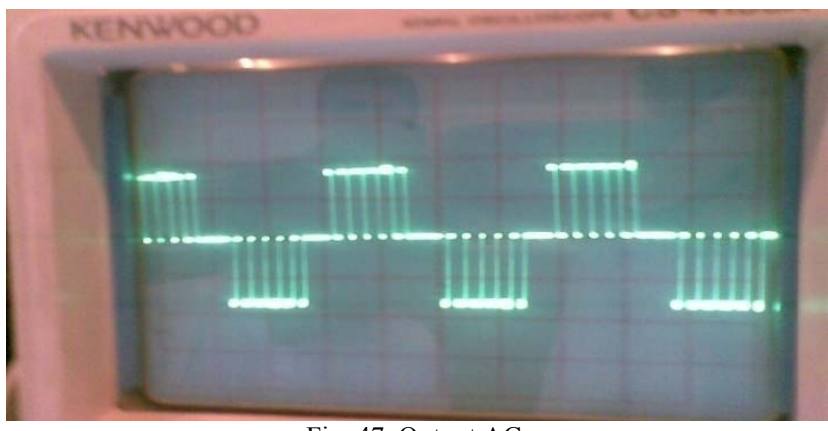

Fig. 47. Output AC

\section{CONCLUSION}

This paper presents analysis of different voltage control signal techniques used for single phase full bridge inverter. Matlab models for voltage control signal techniques and single phase inverter of full bridge type are developed with block of Simulink and same are used for the simulation studies. Simulation results of all above voltage control signal techniques for the single phase full bridge inverter are presented and evaluated with each other with respect to fundamental component of AC load voltage and total harmonic distortion. Best voltage control signal technique, sinusoidal pulse width modulation, is practically implemented for single phase inverter of full bridge type and experimental results are presented.

\section{ACKNOWLEDGMENT}

Indeed we could not have achieved anything without the guidance of Allah Almighty, most merciful of all. We are thankful for the patience and courage he has given us during the course of this project and besides it. Thanks are due, to ALLAH, the Merciful; Truly HE is the best provider. Best wishes and prayers of parents always play an important role in the success. We are very thankful to our parents whom prayers and encouragement give us courage to come up with worth reporting result. May ALLAH Almighty keep in this world and here after (AMEEN). Finally, words alone cannot express the Thanks we owe to our Parents for their endless efforts, encouragement and Assistance. Without their help we could not have reached this far. Their patience, support, tolerance and blessings were the driving force for us.

\section{REFERENCES}

[1] M. H. Rashid, "Power Electronics Circuits, Devices, and Applications," $3^{\text {rd }}$ ed, Prentice Hall Intl, ch.6, pp. 248-260. 2007.

[2] D. N. Sonawane, M. S. Sutaone, B. N. Choudhari, and A. Badurkar, "FPGA Implementation of Simplified SVPWM Algorithm for Three Phase Voltage Source Inverter," International Journal of Computer 
and Electrical Engineering, Vol.2, No.6, December, pp. 1010-1017. 2010.

[3] S. L. Jung, M. Y. Chang, J. Y. Jyang, H.-S. Huang, L.C. Yeh, and Y. Y. Tzou, "Design and implementation of an FPGA-based control IC for the single-phase PWM inverter used in an UPS," in Proc. $2^{\text {nd }}$ Int.Conf. Power Electronic Drive Syst. (PEDS'97), May 1997, pp. 344-349.

[4] A. M. Trzynadlowski; "Introduction to modern power electronics," Wiley Inter-science, 1998.

[5] S. Jeevananthan, P. Dananjayan, and S. Venkatesan, "A Novel Modified Carrier PWM Switching Strategy for Single-Phase Full-Bridge Inverter," Iranian Journal of Electrical and Computer Engineering, Summer Fall - Special Section on Power Engineering, Vol. 4, No. 2, pp. 101-108, Tehran, Iran, 2005.

[6] N. Aphiratsakun, S. R. Bhaganagarapu, and K. Techakittiroj, "Implementation of a Single-phase Unipolar Inverter Using DSP TMS320F241,” AU J.T. Vol.8, No. 4, pp 191-195, Apr. 2005.

[7] "Atmel AT89s52 datasheet" .[Online] Available: http://www.atmel.com/dyn/resources/prod_documents/doc1919.pdf

[8] B. Ismail and S. T, "Development of a Single Phase SPWM Microcontroller-Based Inverter," First International power and Energy conference PEC, November, 2006, p. 437. Putrajaya, Malaysia: IEEE.

[9] Rectifier, I. IR2110(-1-2) (S) PbF/IR2113(-1-2) (S) PbF HIGH AND LOW SIDE DRIVER Data Sheet. Data Sheet No. PD60147 rev.U.
Athar Hanif, is Assistant Professor of Electrical Engineering Department The University of Lahore, Pakistan, since 2004. He has Bachelor Degree in Electrical Engineering from UET, Taxila, Pakistan in the year of 2003; he received Master Degree from UET, Lahore, Pakistan in the year of 2008. He is currently pursuing doctoral research at UET, Lahore. He has eight years of teaching experience. His fields of interest include Power Electronics, Control Systems, Robotics, Control for Power Electronics Circuits, and Simulation and Modeling.

Asim Mukhtar, has obtained his Bachelor Degree in Electrical Engineering from the University of Lahore, Pakistan in the year of 2009. He is presently a research scholar. He is working in the area of DC to AC converters.

Umar Farooq, did his B.Sc. and M.Sc. both in Electrical Engineering from University of Engineering \& Technology Lahore in 2004 and 2010 respectively. He is currently with the Department of Electrical Engineering, University of The Punjab Lahore. His research interests include the application of intelligent techniques to problems in control engineering, robotics and power electronics

Abid Javed, has obtained his Bachelor and Master Degree in Electrical Engineering from UET Lahore, Pakistan in 2000 and 2004 respectively. Now he is work towards $\mathrm{PhD}$ degree in Electrical Engineering in UET Lahore. His areas of interest are Power Electronics, Analysis of Electrical Machines, Artificial Intelligence, and Machine Learning. 